\title{
A Case of Bony Defect of the Anterior External Auditory Canal Wall Causing Ear Fullness
}

\author{
Jong Kyou Lee, Bum Sang Lee, Soo Kyung Jang, and Su-Kyoung Park (iD \\ Department of Otorhinolaryngology-Head and Neck Surgery, Kangnam Sacred Heart Hospital, College of Medicine, Hallym University, \\ Seoul, Korea
}

\author{
이충만감을 유발한 외이도 전벽 골 결손 1 예 \\ 이종규 · 이범상 · 장수경 · 박수경 \\ 한림대학교 의과대학 강남성심병원 이비인후-두경부외과학교실
}

\author{
Received March 8, 2019 \\ Revised May 13, 2019 \\ Accepted May 20, 2019 \\ Address for correspondence \\ Su-Kyoung Park, MD, PhD \\ Department of Otorhinolaryngology- \\ Head and Neck Surgery, \\ Kangnam Sacred Heart Hospital, \\ College of Medicine, \\ Hallym University, \\ 1 Singil-ro, Yeongdeungpo-gu, \\ Seoul 07441, Korea \\ Tel $+82-2-6960-1270$ \\ Fax $+82-2-6960-1264$ \\ E-mail ashock@hanmail.net
}

\begin{abstract}
A congenital defect of the anterior wall of the external auditory canal (EAC) is known as foramen of Huschke. The tympanic bone is incompletely developed and has a $U$ shape at birth. The foramen of Huschke closes via continuous bone growth, which occurs before the age of 5 years. A persistent foramen of Huschke is an anatomic variation located in the anteroinferior portion of EAC, which can cause ear discomfort with spontaneous temporomandibular joint (TMJ) herniation into the EAC bony defect. We present a case of 50-year-old man who had a symptomatic TMJ herniation through an osseous defect. The physical examination showed a bulging mass of anterioinferior portion of EAC when the patient closed his mouth, which was retracted when the mouth openned. We report a case of surgical reconstruction of the EAC wall defect, and the foramen of Huschke with titanium mesh via preauricular approach along with literature's review. Korean J Otorhinolaryngol-Head Neck Surg 2020;63(3):129-33
\end{abstract}

\section{서 론}

선천적인 외이도 골 결손은 다른 용어로 개방성 foramen of Huschke로 불리는데 그 비율은 카데바 연구에서는 약 $7.2 \%$, 고해상도 측두골 단층촬영을 통해서는 약 $1.5 \sim 4.6 \%$ 에 서 발견된다고 알려져 있다. ${ }^{1)}$ 외이도를 이루고 있는 골부의 형태는 선천적으로 불완전한 U자 모양을 이루고 있는데, 약 1 세경부터 전방 및 후방 돌출 부분이 자라고 서로 융합하여 만 5 세경에는 완전히 성장하여 외이도가 원의 형태로 닫히 게 된다. 하지만 일부 환자에서는 골 결손이 5 세 이후에도 유 지되는 경우가 있고 이를 개방성 foramen of Huschke라고 한다.1) 개방성 foramen of Huschke 환자의 경우 드물게 악

This is an Open Access article distributed under the terms of the Creative Commons Attribution Non-Commercial License (https://creativecommons.org/licenses/by-nc/4.0) which permits unrestricted non-commercial use, distribution, and reproduction in any medium, provided the original work is properly cited.
관절이 외이도로 이탈할 수 있으며 이는 전체 인구의 약 $0.4 \%$ 에 해당된다. ${ }^{2,3)}$

외이도 골 결손의 환자 중 일부에서는 이통, 저작 시 악관 절 통증 또는 이명, 잦은 외이도염, 전도성 난청, 외이도를 통 한 침의 분비와 같은 증상을 나타낸다. 저자들은 우측 이충 만감과 저작 시 이명을 주소로 내원한 환자에서 우측 외이도 골 결손 및 우측 악관절 탈출을 진단하고 이를 전이개 접근 을 통해 티타늄 메시를 이용하여 수술적으로 재건하여 치료 한 경험을 문헌 고찰과 함께 보고하는 바이다.

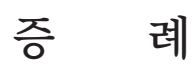

50 세 남자 환자가 약 2 주 전부터 자연히 발생한 우측 이충 만감과 저작 시 우측 이명을 주소로 본원에 내원하였다. 약 20년 전에 악관절이 빠진 적이 있었으며, 이후 입을 벌리거나 
다물 때 우측 악관절에서 소리가 나는 경향이 있었으나 특별 한 치료는 받지 않았다. 그 외에 당뇨, 고혈압 및 특이적인 치 과 수술의 병력은 없었다. 이내시경을 이용한 이학적 검사에 서 우측 외이도 전하벽으로 돌출된 종괴가 관찰되었으며, 입 을 다물 때는 돌출되었으나 입을 벌릴 때는 사라지는 양상이 었다. 이 외에 고막을 비롯하여 다른 구조물에서는 특이적인 소견이 보이지 않았고, 이관 기능도 정상이었다. 시행한 측두 골 전산화단층촬영에서 우측 외이도 전벽에서 약 $3.5 \times 5.8 \mathrm{~mm}$ 의 골 결손으로 인해 우측 외이도 전하벽으로 연조직의 팽윤 소견을 보이고 있었다(Fig. 1). 순음청력검사상에서는 우측 기 도청력 $6 \mathrm{~dB}$, 좌측 기도청력 $9 \mathrm{~dB}$ 로 정상 소견을 보였으며, 고막운동성 검사에서도 양측 $\mathrm{A}$ 형으로 정상 소견을 보이고 있 었다. 악관절 자체에 문제가 없는지 치과 자문을 의뢰하였으 며 특이 소견이 없음을 확인하였다. 환자에게 우측 외이도의 선천적인 골 결손에 의해서 우측 악관절이 이탈하였으며, 증 상이 없거나 일상생활에서 불편감이 크지 않을 경우 우측으 로 무리하게 씹는 것을 조심하면서 수술적 치료 없이 보존적 으로 지켜보는 경우도 있음을 설명하였으나 본 증례의 환자 는 저작 시에 우측 이충만감으로 일상생활의 불편감을 느낀 다고 호소하여서 수술적 치료를 시행하기로 하였다.

수술은 경비기관 내 삽관을 통한 전신마취하에 전이개 접 근을 통해 절개를 하였다(Fig. 2A). 이주 연골 외측 및 아래 쪽으로 박리를 시작하여 장비경과 견인기를 이용하여 시야 를 확보하였다(Fig. 2B). 전이개 부분이 충분히 박리가 진행 된 후 외이도의 팽윤된 부위에 26게이지 천자침을 넣어 병변 의 위치를 가늠할 수 있도록 하였다(Fig. 2C). 또한, 구강 견 인기로 입을 벌렸다 닫는 작업을 통해 정확한 병변의 위치를 확인하였다(Fig. 2D). 외이도 골성 부분과 악관절낭과의 접합 부분을 관절낭이 열리지 않도록 주의하여 박리한 후 외이도 의 골부와 악관절조직 사이의 공간을 확보하였다(Fig. 3). 골 결손 부위의 크기는 측두골 전산화단층촬영 소견과 $\mathrm{T}$ 자를 이용하여 가늠하였으며, 티타늄 메시(MicroMesh ${ }^{\circledR}, \operatorname{stan}^{-}$ dard 54-00272, Stryker, MI, USA)를 4×6 mm 크기로 재
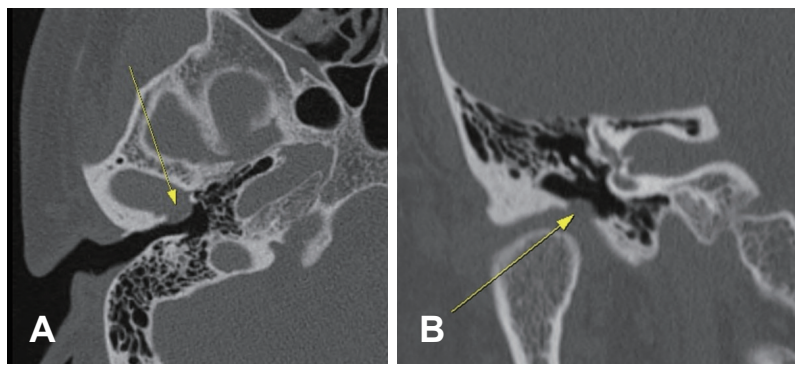

Fig. 1. Temporal bone CT scan of the external auditory canal structure. Preoperative temporal bone CT imaging shows a bony defect of the right anterior external auditory canal (arrows) in axial view (A) and coronal view (B).
단하여 삽입하고, 외이도의 상태가 양호함을 확인하였다. 메 시를 삽입하고 박리한 조직을 조직층별로 봉합한 후, 외이도 는 나일론 스트립과 거즈를 이용하여 패킹을 시행하였다. 수 술 후 2일째 출혈이나 이루, 통증 없이 퇴원하였고 2주째 외 래에서 전이개 부분 봉합사를 제거하였다. 환자는 입을 벌릴 시에 경미하게 악관절 통증을 호소하여 지속적으로 입을 심 하게 벌리거나 딱딱한 음식을 드시지 않도록 설명하였다. 수 술 후 3주째 외이도 약간의 이물감과 통증 외에 특이 소견이 없어 외이도 패킹을 제거하였고, 입을 벌리거나 닫을 때 외이 도 전벽의 돌출이 없음을 확인하였다(Fig. 4). 이후 특별한 증
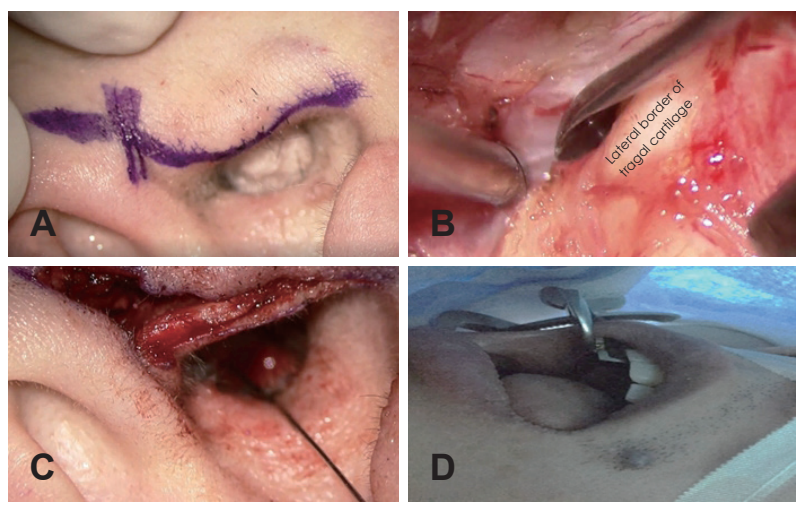

Fig. 2. Operation procedures under general anesthesia through nasotracheal intubation. Preauricular incision line (A). Tragal cartilage was exposed and dissection was done at the lateral border of the tragal cartilage (B). Bulging mass was pricked by 26-gauge spinal needle to probe the exact bony defect site (C). Mouth retractor was used for opening and closing the mouth during operation (D).

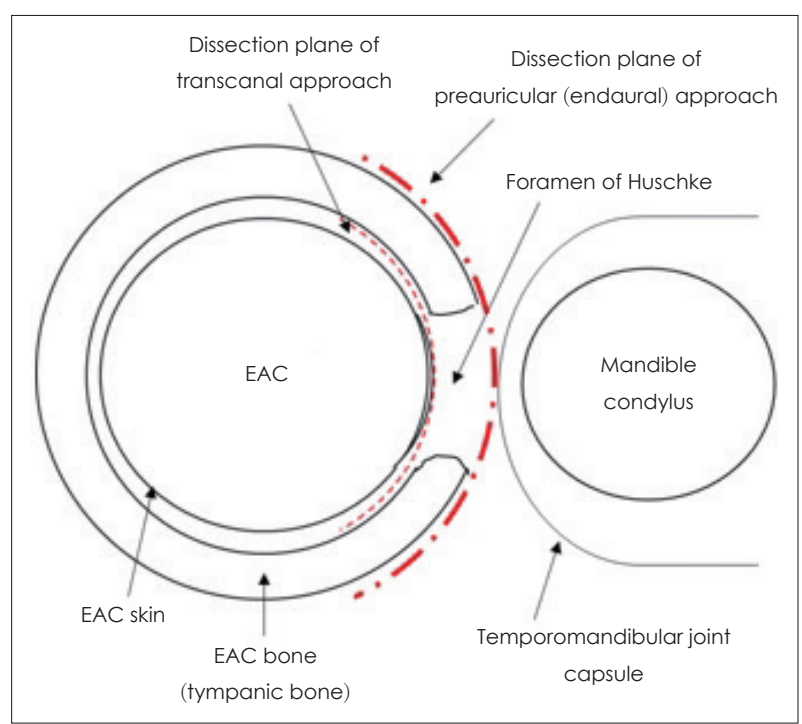

Fig. 3. Schema illustrate the approach plane for the repair of foramen of Huschke. The dissection plane of transcanal approach is the space between skin of EAC and inner surface of bony EAC (simple dot line) and the plane of preauricular approach is between outer surface of bony EAC and capsule of temporomandibular joint (dash and dot line). EAC: external auditory canal. 

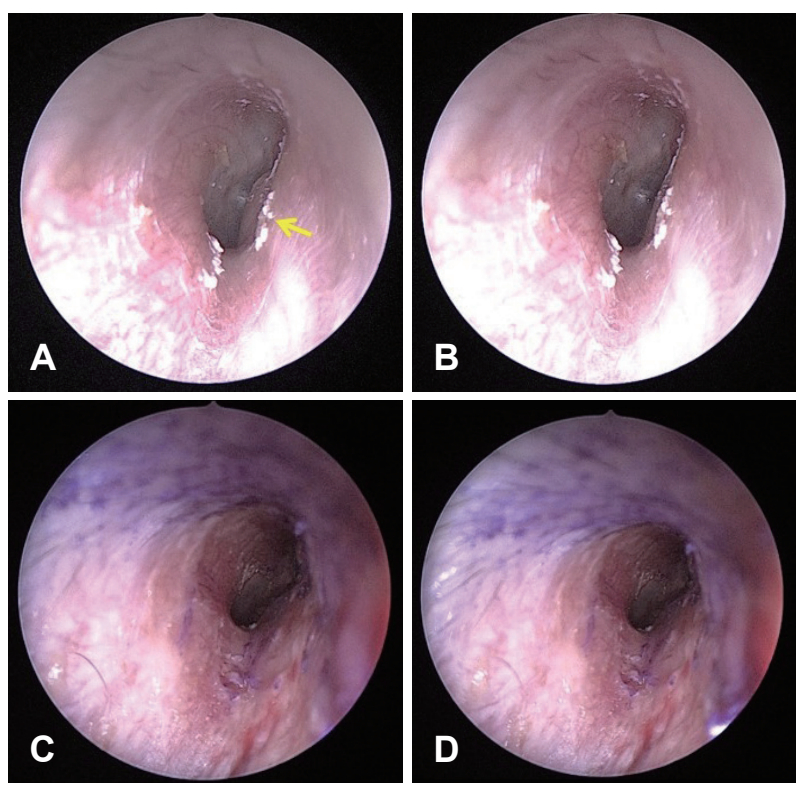

Fig. 4. Ear endoscopic findings before and after the repair of foramen of Huschke. Preoperative ear endoscopy shows a round bulging mass-like lesion (arrow) of anterior external auditory canal when mouth closing $(A)$ and the bulging area vanishes when mouth opening (B). Postoperative 3 weeks' ear endoscopy shows no definite protruding lesion during mouth closing $(C)$ and opening (D).

상 없이 수술 후 6개월간 외래 추적 관찰하였으며 재발이나 다른 합병증은 발생하지 않았다.

\section{고 찰}

선천성 외이도 골 결손은 5세 이후에도 외이도를 이루고 있는 골 형태가 완전히 유합되지 않아서 생기게 되는 질환으 로 개방성 foramen of Huschke는 1987년 Hawke 등헤에 의 해 처음 보고되었다. Foramen of Huschke와 악관절이 외이 도로 이탈에 대해 총 65 편의 문헌이 검색되었는데, 유병률이 나 진단 방법에 대한 보고를 제외하고 증상을 유발하는 foramen of Huschke 환자에 대한 임상 증례를 언급한 논문은 2005년 이후 총 28편이 보고되었다. 개방성 foramen of Huschke 으로 외이도의 골 결손이 있더라도 무증상인 경우가 대부분 이며, 일부 환자들에서 드물게 악관절 탈출이 발생하고 저작 운동으로 인해 악관절의 윤활막 조직이 외이도 골 결손 부위 로 이탈하고 이로 인해 이차적으로 골 결손 부위가 점차 커지 게 되어 이충만감, 이통, 악관절 통증, 저작 시 이명, 전도성 난 청 등을 유발하게 된다. ${ }^{1-10)}$ 또한 타액루가 외이도 골 결손 부 분으로 발생하여 이루를 유발하거나 이차적으로 육아조직이 발생할 수도 있어 외이도염으로 오인되기도 한다. ${ }^{8,9,11-13)}$ 외이 도 골 결손 환자의 악관절의 외이도 이탈을 처음 진찰 시 의 심하고 진단하기 위해서는 이내시경 검사상 입을 다물면 외 이도 종물의 소견이 관찰되고, 입을 벌리면 악관절이 전방으
로 이동하면서 외이도 종물이 사라지거나 줄어드는 소견을 확인해야 한다. ${ }^{2,6)}$ 환자가 불편함을 호소하는 증상이 있는 경 우 외이도 결손 부위를 막기 위해 이식물을 이용하여 외이도 부위를 재건해 주는 수술이 필요하다. 2,3,5-13)

이충만감을 동반하는 외이도의 종물은 개방성 foramen of Huschke 외에도 드물지만 악관절의 정맥기형, 혈관종, 결 절종, 골종에 의해서도 나타날 수 있으며, 그 외 증상으로 악 관절 통증, 개구장애, 악관절 부위의 마찰음이 발생할 수 있 다. 또한 외이도 종물은 악성 외이도염, 외상, 악관절의 염증, 진주종, 이하선 종양 등으로도 외이도 전벽의 결손을 유발하 거나 결손 부위를 통해 해당 질환이 침범할 수 있으므로 다 양한 질환 등을 고려하여 감별하는 것이 필요하다. $2,14,15)$ Choe 등 ${ }^{14)}$ 은 외이도 종물에 대해서 측두골 전산화단층촬영 검사 및 자기공명영상 검사를 시행 후 외래에서 절개 생검을 시행 하였으나 표면의 정상 피부만 채취되어 조직병리 진단을 얻지 못했고 수술적 제거를 통해 악관절의 정맥기형을 진단하였다. Misra 등히는 15 년 전부터 개구장애가 있었던 22세 환자에서 전산화단층촬영 검사를 시행한 후 악관절 돌기 주변으로 3.2 $\mathrm{cm}$ 크기의 종물 소견이 보여 수술적인 치료를 통해 악관절 돌기절제술을 시행하였고 악관절 골종을 진단한 바 있었다. 본 증례에서는 다른 질환을 감별하기 위해 외래 귀 내시경 검사 시 단순히 외이도만 관찰하는 것이 아니라 입을 벌리고 다물 때 외이도의 전벽 종물의 크기가 변하는 것을 관찰하 였고 이를 통해 외이도 전벽 골부 결손을 가장 의심하게 되었 다. 결손의 범위와 추가 동반 질환의 유무를 확인하기 위해 시 행한 측두골 전산화단층촬영 검사상 외이도 종물이나, 진주 종, 악관절 종물이나 악관절 자체의 이상 소견은 보이지 않아 외이도 종물에 대한 추가적인 조직 검사는 시행하지 않았다.

증상이 없는 외이도의 골 결손 환자는 특별히 치료를 하지 않으나 이충만감, 이통, 악관절 통증, 이명, 전도성 난청 등의 증상이 있는 외이도 골 결손은 수술적 외이도 재건이 근본적 인 치료 방법이다. 외이도 골 결손의 재건을 위해 현재까지 사용되는 재료로는 이주 연골, 측두근 근막, 피부, polyethylene, polypropylene, 콜라겐 메시, 티타늄 메시 등이 있다. 이주 연골과 측두근 근막을 사용하여 외이도 골 결손을 막은 경우 가능한 합병증으로는 생체 이식물이 흡수되거나 이탈 될 가능성이 있다고 알려져 있다.,5-8,11-13) 외이도 재건을 위한 수술적인 접근 방법으로는 크게 두 가지 방법이 있다. 외이 도 접근법은 상처가 외부로 노출되지 않는 장점이 있고 수술 자의 시점에서는 친근한 접근법이지만 이식물이 결손 부분 을 통과해야 하기 때문에 이식물의 크기가 결손 부분의 크기 보다 더 작아야 된다. ${ }^{2,6,10)}$ 또한 외이도의 피부 피판과 골부 외이도 사이에 재건된 이식물 위에 놓여야 하기 때문에 피판 
문제를 유발할 수 있다. 전이개 접근법은 이개와 이륜 앞부분 에 절개가 되는 단점이 있지만 수술 시 외이도 접근법보다 더 넓은 시야를 제공하고 골 결손 부분보다 더 큰 이식물을 삽 입할 수 있는 장점이 있다(Fig. 2). 2,3,5,7-9,12,13) 전이개 접근법으 로 수술 시 외이도 골부 앞부분과 악관절의 사이 부분을 박 리해야 하는데, 본 증례에서는 외이도 피부가 악관절낭과 유 착이 없었으나 유착이 있는 경우 악관절낭 쪽으로 박리 기구 가 들어가 찢어지지 않도록 기구의 방향과 힘 조절에 주의하 여 조심히 박리해야 할 것이다(Fig. 3). 전이개 접근법으로 수 술할 경우 시야가 평소 이과 수술에서 접근하는 부위가 아니 기 때문에 보다 병변의 위치를 잘 확인하기 위해 수술 중 구 강견인기를 통하여 입을 열고 닫아서 외이도의 돌출 여부를 확인하면서 박리하거나, 결손 부위에 탐침을 이용하면 정확 한 부위를 확인하고 박리하는 데에 도움이 될 수 있다. 이를 위해서는 경비기관 내 삽관을 시행하는 것이 필요하다. 통상 적으로 전이개 접근법은 외이도 패킹이 필요하지 않으나, 본 증례에서는 외이도 결손 부위를 통해 천자침을 넣어 수술 부 위를 확인하는 과정에서 외이도 피부 미란이 발생하여 수술 후 외이도 패킹을 시행하였다.

저자들은 2005년 이후 최근 15년간 보고된 관련된 논문 들을 분석하였고 증상을 유발하는 외이도 골 결손에 대한 증례를 발표한 총 28편의 논문 중에서 환자가 수술을 거부 한 증례를 제외하고 실제로 외이도 골 결손 부위에 대해 재 건 수술을 진행한 12 편의 논문에 대해 임상적 양상과 수술 적 방법을 분석하였다(Table 1). ${ }^{1-3,5-13)}$ 총 18 명의 환자가 대상 이었고 그중 양측성으로 발병한 1명의 환자를 고려하면 총 19 개의 귀에서 수술을 진행하였고, 우측은 9건, 좌측은 10건 으로 좌측이 약간 더 많았다. 보고된 19개의 증상이 있는 foramen of Huschke 증례는 단일 증상보다 다양한 증상들 을 같이 호소하는 경우가 대부분이었다. 증상 중 이명이 9건 (전체 중 47\%)으로 가장 흔한 증상이었고, 타액루 형성으로 인한 이루가 8건(42\%), 전도성 난청이 6건(32\%), 이충만감과 이통이 각각 5건(26\%), 악관절 통증(2건, $11 \%$ ) 순서로 많았 다. 통상적인 보고에 의하면 타액루로 인한 이루 증상은 드 물다고 하였으나, 실제 문헌에 보고된 18건의 보고 중 8건에 서는 이루를 주 증상으로 내원하였고, 일부에서는 처음 진단 시 외이도염으로 오인되었다고 보고하였다. ${ }^{8,911-13)}$ 결손된 외 이도를 재건하기 위한 재료로는 이주 연골을 사용한 경우가 6건, 측두근 근막을 이용한 방법은 4건, 육아종 제거와 피부 이식은 2건, 콜라겐 메시 1건, 티타늄 메시를 이용한 방법은 7건으로 티타늄 메시를 이용한 경우가 전체 재료 중 $37 \%$ 를 차 지하여 가장 많았다. 수술적 접근 방법으로는 전이개 접근법 이 12 건(67\%)으로 가장 많았고, 외이도 접근법은 5건(28\%),

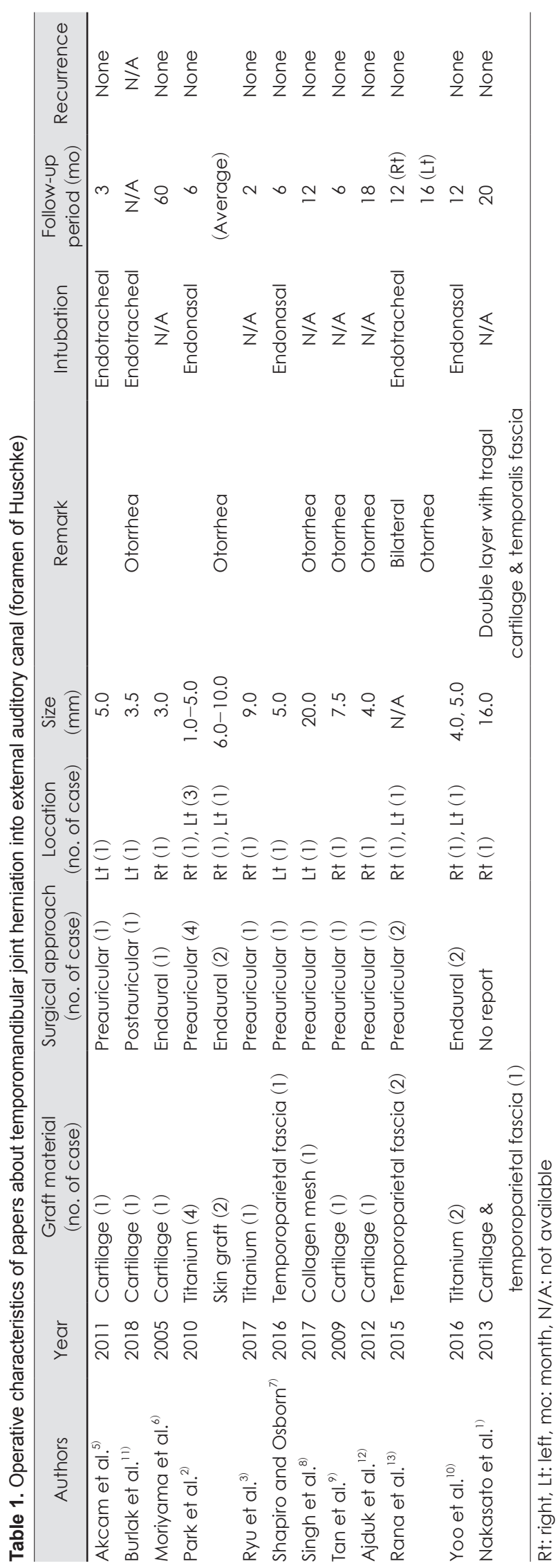


후이개 접근법은 1 건(5\%)이 있었다. 대체적으로 결손 부위가 $5 \mathrm{~mm}$ 이상으로 크기가 클 경우 티타늄을 사용하고 전이개 접근법을 사용하는 경향이 많았고 위 증례에서 모두 재발에 대한 보고는 없었다. ${ }^{2,3}$ 반면 외이도에서 이루가 동반된 경우 에서는 티타늄과 같은 외부 물질을 사용하여 골 결손을 재건 하기보다는 생체 흡착에 유리한 이주 연골이나 측두근 근막 을 이용하여 재건을 하였다. ${ }^{8,911-13)} 12$ 개의 논문 중 3 개의 논 문에서는 수술 중 입을 열거나 닫을 수 있어서 골 결손 부분 을 정확히 가늠할 수 있다는 장점이 있는 경비기관 내 삽관을 통해 수술을 진행하였고, ${ }^{2,710)}$ 다른 3 개의 논문에서는 구강을 통한 기관 내 삽관을 시행하였다. ${ }^{5,11,13)}$ 나머지 6개의 논문에서 는 기관삽관 방법에 대한 특별한 언급이 없었다.,1,6,8,9,12) 조사한 문헌들의 고찰에서 이론적으로는 이식물의 돌출이나 감염 등이 발생할 수 있다고 언급하였으나 조사한 모든 문헌의 증 례에서 관찰한 기간 중 합병증이나 재발에 대한 보고는 없었 다. ${ }^{2,35-13)}$ 이는 조사한 문헌들이 1 예를 제외하고 대부분 1 년 내외로 관찰하였기 때문으로 여겨지며 보다 오랜 기간 동안 추적 관찰한 연구가 필요하다.

본 증례에서는 넓은 시야를 확보하고 결손 부위를 메꾸는 이식물을 제 위치에 삽입하기 위해 전이개 접근법을 통해서 수술하였고 골 결손의 크기가 약 $6 \mathrm{~mm}$ 로 비교적 큰 편이며 이루가 동반되지 않았기 때문에 이물 반응이 적고 강도가 강한 티타늄 메시를 이용하여 재건하였다. ${ }^{2)}$ 아울러 티타늄 메시는 이식물을 채취하는 과정이 생략되어 수술 시간을 단 축할 수 있고, 크기에 맞게 재단하기가 용이하다는 장점이 있다. 본 증례의 환자는 수술 후 저작 시 경미하게 악관절 불 편감을 호소하였으나 3주경에 증상이 호전되었고 수술 후 6 개월 정도 추적 관찰 결과 이학적 검사상 외이도 종물 또는 이식물의 돌출 소견은 보이지 않았다.

저자들은 우측 이충만감 및 저작 시 우측 이명을 호소하 는 환자에서 이내시경 검사 및 청력 검사, 영상 검사를 면밀 히 진행한 뒤 티타늄 매시를 이용하여 외이도 재건을 통해 우 측 악관절 탈출을 치료하였기에 문헌 고찰과 함께 보고하는 바이다.

\section{Author Contribution}

Conceptualization: Su-Kyoung Park. Data curation: Jong Kyou Lee. Formal analysis: Jong Kyou Lee. Investigation: Jong Kyou Lee, Soo Kyung Jang, Bum Sang Lee. Methodology: Jong Kyou Lee. Project administration: Su-Kyoung Park. Resources: Jong Kyou
Lee. Software: Soo Kyung Jang. Supervision: Su-Kyoung Park. Validation: Jong Kyou Lee. Visualization: Bum Sang Lee. Writingoriginal draft: Jong Kyou Lee. Writing - review \& editing: Jong Kyou Lee, Soo Kyung Jang, Bum Sang Lee.

\section{ORCID}

Su-Kyoung Park https://orcid.org/0000-0002-2274-2799

\section{REFERENCES}

1) Nakasato T, Nakayama T, Kikuchi K, Ehara S, Ohtsuka H, Fukuda $\mathrm{K}$, et al. Spontaneous temporomandibular joint herniation into the external auditory canal through a persistent foramen tympanicum (Huschke): Radiographic features. J Comput Assist Tomogr 2013; 37(1):111-3.

2) Park YH, Kim HJ, Park MH. Temporomandibular joint herniation into the external auditory canal. Laryngoscope 2010;120(11):2284-8.

3) Ryu KH, Baek HJ, Hur DG. Spontaneous temporomandibular joint herniation into the external auditory canal through a patent foramen of Huschke: A case report. Ann Med Surg (Lond) 2017;18:33-5.

4) Hawke M, Kwok P, Mehta M, Wang RG. Bilateral spontaneous temporomandibular joint herniation into the external auditory canal. J Otolaryngol 1987;16(6):387-9.

5) Akcam T, Hidir Y, Ilica AT, Kilic E, Sencimen M. Temporomandibular joint herniation into the external ear canal through foramen of Huschke. Auris Nasus Larynx 2011;38(5):646-9.

6) Moriyama M, Kodama S, Suzuki M. Spontaneous temporomandibular joint herniation into the external auditory canal: A case report and review of the literature. Laryngoscope 2005;115(12):2174-7.

7) Shapiro MC, Osborn T. Temporoparietal fascia flap and total temporomandibular joint replacement for the management of patent foramen of Huschke. Int J Oral Maxillofac Surg 2016;45(8):1023-6.

8) Singh I, Jain A, Prasad P, Rajpurohit P. Spontaneous temporomandibular joint herniation: A rare case. Oral Maxillofac Surg 2017;21(1):87-90.

9) Tan NC, Wilson A, Buckland J. Herniation of the temporomandibular joint into the external auditory meatus secondary to benign necrotising otitis externa. Br J Oral Maxillofac Surg 2009;47(2):135-7.

10) Yoo MH, Park JW, Lee HS, Yang CJ, Park HJ. Repair of the foramen of Huschke using an extended endaural approach. Laryngoscope 2016;126(9):2137-9.

11) Burlak K, So TY, Maclaurin WA, Dixon AF. Foramen tympanicum with symptomatic temporomandibular joint herniation. Radiol Case Rep 2018;13(4):822-4.

12) Ajduk J, Ries M, Vagic D, Batos-Tripalo A. Temporomandibular joint fistula into the external ear canal. J Laryngol Otol 2012;126 (8):837-9.

13) Rana K, Rathore PK, Raj A, Meher R, Wadhwa V, Prakash A, et al. Bilateral spontaneous salivary otorrhoea: Case report and a review of the literature. Int J Pediatr Otorhinolaryngol 2015;79(10):1774-7.

14) Choe S, Lee D, Kang MS, Heo KW. A case of venous malformation in temporomandibular joint causing stenosis of external auditory canal. Korean J Otorhinolaryngol-Head Neck Surg 2019;62(5): 299-302.

15) Misra N, Srivastava S, Bodade PR, Rastogi V. Osteoma of temporomandibular joint: A rarity. BMJ Case Rep 2013;2013: bcr2013200268. 